\title{
PRISON LIBRARIES INSIDE OUT
}

\author{
by \\ Glen Singer
}

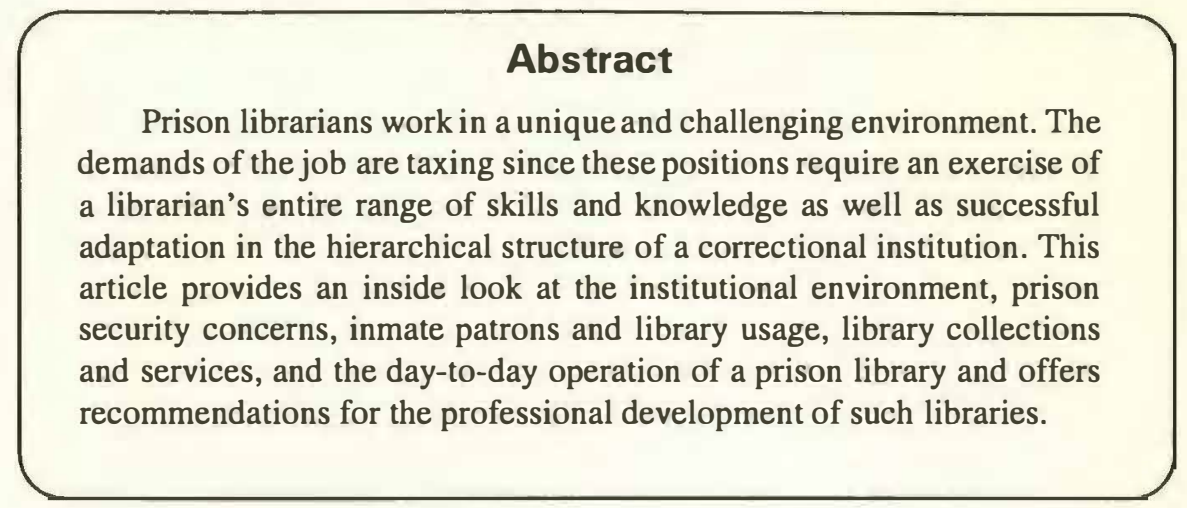

In 1986, I accepted the position of librarian at Columbia Correctional Institution (CCI), Portage, Wisconsin. CCI was the first new prison facility built in Wisconsin in twenty-four years. It was designed to be a maximum-security institution whose mission was to house 450 inmates-the so-called "worst of the worst" in the Wisconsin Correctional System. At the time of my arrival, I had previously spent six years with the Department of Corrections in an administrative capacity and as a librarian at a minimum-security prison. As a result, I was probably not adequately prepared for the challenge of both building a library from scratch and dealing with a potentially problematic, volatile, and dangerous clientele, nor was I sufficiently inured to the stringent security necessary to operate such an institution.

Since that time the CCI Library has grown and evolved into a full-fledged program unit which provides services to the entire prison community. During this period, CCI's population has almost doubled to 870 inmates; Wisconsin has built several new prisons, including an even more austere "maximum-maximum security" facility; several more prisons are in the construction phase; and thousands of inmates have been sent out of state to "privatized" prisons. These circumstances reflect the national anti-crime climate that has been cultivated and exploited as a political rallying point during the past two decades-a situation which has resulted in tougher sentencing laws and prisons which are bursting at the seams.

When I began employment in the Wisconsin Department of Corrections, a librarian's position was unique, for there were few trained librarians in the Wisconsin prison system. Libraries were often managed by teachers on a part-time basis or run by inmates with minimal supervision. At some institutions, libraries were next to non-existent. Since that time, the number of correctional libraries has grown, while their management has become increasingly professional. Library school graduates are routinely placed in the correctional and institutional setting, yet there are few academic programs or individual courses which train librarians for the unique challenges of such employment. When new librarians arrive at their jobs, they are often less prepared than I was for those elements which differentiate prison librarianship from its kindred disciplines. When a librarian accepts employment in a prison, he or she is entering a world that is far removed fromi the apparent gentility of academia or the seeming normalcy of the public library.

\section{Geography}

The first feeling which is apparent when one enters a correctional institution is that it is a rigidly contained, imploded universe. Upon entrance, one's bags, briefcases, and lunch containers are checked for contraband items. Uniformed guards flank entrances and patrol hallways. Door after door, some with iron bars, open and shut behind each employee after proper identification is established. The prison library is embedded in this context. Almost universally, it is limited in terms of space and often is tucked into an inconvenient corner-almost a spare part between the gym and the kitchen or buried in the basement of the education building. This space is usually split between a general and a law library. Total library capacity rarely exceeds forty patrons. The area is often spartan, either by design or necessity: bare tile floors, concrete block walls, acoustic-tile drop 
ceilings, formica-topped tables, plastic scoop chairs, no air-conditioning in the summer, and inadequate heat in the winter. At levels of lower security rating (e.g., medium- or minimum -security), library appointments tend to be more "luxurious", as wall hangings or other decorative art, wooden shelves, padded chairs, and carpets sof ten the environment. The placement of every object in the library is dictated by concerns for institutional security and safety. Low shelves are often employed, and shelf rows are arranged so that the librarian or security officer may have open sight lines down aisles. Mirrors and cameras are used to cover blind spots and monitor inmate movement.

\section{Patrons}

Prison library patrons are convicted felons whose crimes range from drunken driving to mass murder. A patron sample would show that generally prison library users are disadvantaged educationally, of ten learning disabled, psychologically and emotionally unstable, and self-absorbed. In recent years, the mentally ill have become a large minority in the corrections continuum. A 1998 report on inmates at Columbia Correctional Institution revealed that $26 \%$ were serving life sentences or the equivalent; another $40 \%$ were sentenced to more than ten years in prison; $75 \%$ had been convicted for violent, assaultive offenses; $60 \%$ were diagnosed with mental health needs; $69 \%$ were assessed with alcohol or drug treatment needs; $24 \%$ were identified as gang members. According to assessment and evaluation testing, 65\% required basic educational programming, while $70 \%$ were listed as having vocational needs. Approximately $30 \%$ of the population were functionally illiterate. Though these figures characterize the extreme environment of a maximum-security institution, the statistics for mental illness, alcohol/drug needs, and education are also fairly typical of institutions at lesser levels of security. Obviously, the majority of the prison library's clientele have special needs, and it is within this context that the librarian must function on a day-to-day, face-to-face basis. All decisions from material selection to personal demeanor must be predicated upon a constant awareness of the unique character of the prison population.

\section{Security}

The function of a prison is to segregate its inmates from general society. It is entrusted with housing, feeding, and protecting its wards. The system which it imposes on inmates is deprivational, for it usurps the individual's control of his or her life and vests it in the hands of the state. Thus, the very nature of the stewardship is negative. It is this mission which ultimately overrides all other considerations and circumstances in corrections. The library, along with other program departments, such as recreation, chapel, education, and clinical services, are entrusted with the rehabilitative aspects of incarceration. The mission of these units is positive: improving the daily life of inmates and providing them with long-term skills, training, and treatment. This situation affects prison librarians in two ways. First, they may of ten come into conflict with security personnel over the management of the library since each maintains a different perception of their respective roles. Conflicts routinely arise over the types and quality of information delivered to inmates (i.e., censorship), the breadth of library programming (e.g., use of automation, on-line technology, etc.), and the relationship of the librarians to their patrons (i.e., perceived fraternization). Secondly, the very nature of the position of prison librarian carries an implicit duality. The librarian is expected to assume security functions, such a monitoring inmates, intervening in patron disputes, initiating disciplinary actions, and providing security-oriented policies and procedures to govern the administration and management of the library. Because of these factors, such concepts as the Library Bill of Rights, Intellectual Freedom, and First Amendment freedoms become blurred and subject to pragmatic interpretation. The prison librarian must become very flexible in his or her approach to librarianship and becontinually cognizant of the fact that the greater good sometimes must be purchased at the cost of principle. It is only through such utilitarian compromise that the positive mission of the library can be maintained.

If there are problems in the institution at-large or in the library (e.g., passing or concealing of contraband items, dishonest activity by library clerks, fighting, gang activity, etc.), the library may be locked down and subject to an intense security search. Such searches are conducted by security officers and focus on every item in the library. All library books and materials are scanned, and work areas are efficiently torn apart. The result is complete chaos. When the search is completed, the library, for all practical purposes, must be reassembled-piece by piece. Though this procedure is designed to guarantee the security of both staff and patrons, it is extremely stressful and debilitating from the librarian's perspective. It also provides a clear reminder that security is the master.

\section{The Model}

The most common prison library model is the public library. This construct is based upon the notion that the entire prison population-inmates, administrators, staff, and security personnel-comprises a microcosmic community. Since the library is in reality designed to serve mainly the inmate population, the major goal of the librarian should be to establish a "normalizing" environment within the prison. Ideally, the library should provide a haven for inmates, for it is one of the areas within the institution that is least encumbered by restrictions and rules. It is one of the few places in which incarcerated persons can approach the same freedom that they had on the streets. The "normalizing" model assumes many roles: the library may be a place of recreation, an extension of the classroom, an information center, or a place for exchanging and sharing of ideas. Within this context, it is 
important to maintain the vitality of the library and respond efficiently and positively to inmate needs. The library's role for other members of the prison community may be active, but it is decidedly secondary, for staff members have access to library services and other information sources (e.g., the Internet) outside the prison walls. The library is in reality a source of support for staff. Program materials aimed at inmates may be placed there; technical materials may be obtained from outside sources through its agency; or it may provide an occasional reading and reference resource. It does not, however, have the impact or importance for staff that it does for those for whom it is the only source of information and intellectual growth.

\section{Library and Librarian}

In Wisconsin and other states, a single professional librarian staffs most prison libraries. Though inmates are usually employed to handle basic clerical tasks (e.g., accession, circulation, easy reference, etc.), correctional librarians are responsible for all phases of library administration and management, as well as provision of direct service to inmates. They must handle the details of their budgets, select all materials for the general collection, prepare purchasing documents, hire, train and manage inmate clerks, orchestrate and maintain library automation initiatives, coordinate record-keeping, prepare library reports, catalog incoming materials, perform general and legal reference tasks, insure law library standards, assemble bibliographies, initiate inventories and weeding, perform interlibrary loan duties, participate in grantwriting activities and special library projects, and provide a host of ancillary services (e.g., photocopying for inmates, notary service, etc.). In addition, they are often viewed by prison administrators as institutional factotums and assigned duties outside the library. During my tenure at CCI, I have served as a member of the Program Review Committee (for determination of inmate assignments) and the Due Process Committee (for judgment of inmate disciplinary infractions), and I have been assigned to be an inmate advocate (representing inmates at due process hearings). I was also entrusted with the task of designing, writing, and producing two one-hundred-plus page annual reports for the institution. I am currently a member of the Program Services Committee and the Workplace Enhancement Committee. Such duties exemplify the overlapping nature of the correctional librarian's situation in which he or she is viewed not as specialized professional, but as a useful and exploitable unit within the corrections' hierarchy.

The prison librarian's position is one of professional isolation. The prison library is an anachronism since it founded upon the labor-intensive model, which is the essence of the whole institution. Inmate workers, rather than professional staff, provide support in the library, and the librarian is without any sort of daily contact with peers. Because inmates are prohibited from utilizing on-line tools, the library is forced to rely upon stand-alone technology, a local area network, and CD-ROM materials. Thus, a large portion of the information technology, which has burgeoned in the past twenty years, is also unavailable to the librarian. He or she is cut off from developments in the field, having no access to the fruits of automation, such as myriad databases that are available at other libraries. In addition, he or she begins to develop the internalized vision that characterizes correction employees in general, an "us-against-them" perspective. There is also the danger of institutionalization, for after dealing with inmates and other correctional staff for eight or more hours a day, one may begin to perceive the world by inmate standards. The actuality of crime becomes diminished until it seems almost the norm. The librarian must continually struggle against these factors on a daily basis, and only by doing so is he or she able to maintain his or her professional standards and the integrity of the library.

\section{Library Collections}

Most prison libraries are divided into two distinct segments: the general collection and the law library. Prison administrators regard the latter as the most important element in the entire library operation since its existence is insured by governmental mandate and guarantees inmates free access to the courts. Law or code or other legislation determines its contents. In Wisconsin, the Corrections' Administrative Code spells out the specific publications that are to be placed in the collection. It is comprised of both federal and Wisconsin case law dating back to 1961, state and federal statutes, and appropriate legal treatises and reference materials. It is the most expensive component of the library, and consequently, its jewel. Materials are provided by subscription and blanket order and a librarian's major duty is to order materials in a logical manner and maintain it in a reasonable fashion.

Most librarians who enter correctional systems have little academic preparation in legal librarianship, particularly legal reference service and are prepared neither by position description nor job interview for its importance as a mandated prison program. Thus, they are compelled to tutor themselves in the intricacies of the legal structure and to acquire knowledge of such items as key prison cases, court rules, legal forms, and filing deadlines. The irony of this situation is that few inmates utilize the law library, and even fewer are competent users. Yet, this minority is a very demanding clientele, and the librarian has the daunting task of satisfying the needs of these individuals. The law library also must be carefully monitored because inmates have a tendency to appropriate pages and materials that they deem necessary for personal use. When materials are removed from the library, they must be replaced immediately, always at great cost.

The library's general collection is generally small, ranging from 5,000 to 15,000 hardcover and paperback volumes and other items. Collection size and scope is determined to a large extent by space limitations and security considerations (e.g., shelf height, placement of shelving, etc.). At Columbia Correctional Institution, 
the general collection is made up only of print materials (books and non-circulating periodicals) and several hundred educational videocassettes, which are for staff use only. At lower levels of security, general collections may have greater range and include circulating periodicals, audiocassettes, circulating audio-visual equipment, and CD-ROM based reference services and browsing tools.

Though the prison collection is nominally designed to replicate the collection of a small public library, it has a tendency to skew toward the immediate and the popular, and certain subject areas are emphasized over others. Inmates tend to be voracious fiction readers, and approximately sixty percent of all loans are of popular fiction. Over time, the collection tends to center around certain favorite authors (e.g. Jackie Collins, Stephen King, Dean Koontz, Louis L'Amour, Harold Robbins, Sidney Sheldon, Andrew Vachss, etc.) and genres (e.g., sex-greed-and-power potboilers, westerns, serial-killer thrillers, hard-boiled private eye adventures, fantasy, etc.). Many specific titles are "prison classics" (e.g., Alex Haley's The Autobiography of Malcolm X, William Cooper's Behold a Pale Horse, Harold Robbins' The Carpetbaggers, Claude Brown's Manchild in the Promised Land, Ara Movsesian's Pearls of Love, Machiavelli's The Prince, Stephen King's The Stand, Andrew Vachss's Strega, Jackie Collins' The Stud, etc.) and are literally "read to death". Consequently, a portion of a library's small budget is often expended on replacing or duplicating these popular books. Older fictional materials and classics are of little interest to most inmates. The librarian is continually faced with the dilemma of balancing the collection between the ephemeral and the time-tested.

Non-fiction interest is also concentrated in certain areas, especially true crime, the para-normal, non-Christian religion and mythology, ethnic literature, celebrity biography, and general history. There is very little interest in the sciences, languages, self-help literature, or the arts. In satisfying inmate interests, the librarian is forced to consider the welfare of the inmates, themselves, and to adhere to the guidelines for institutional security. For example, he or she must consider the salutary effects of purchasing true crime materials that detail either visually or verbally crimes of appalling magnitude. Likewise he or she may be forced to reject many popular accounts of ghetto life because they contain vivid descriptions of gang behavior, which are at cross-purpose with security objectives. In addition, certain individual books and types of materials are strictly banned by security on the basis of "penological interest" (e.g., books on martial arts, firearms, organic chemistry, Satanism, etc., as well as those that advocate violence or racial hatred). Prisons have recently begun to control pornography in a more stringent manner than in the past, barring visual and written materials ranging from pin-ups to hard-core pornography. In the prison environment, the librarian is given the responsibility of sifting and winnowing purchases in a much more painstaking manner than is demanded of a public librarian. He or she cannot place implicit faith in reviews, especially in an era when a good deal of literature focuses upon sexuality, violence, and crime. In time, a prison librarian develops an "experienced eye" which enables him or her to detect "red flag" key words or phrases in primary review sources. In such instances, the librarians must then seek out more detailed reviews or do a bit of legwork and examine publications first-hand before purchasing.

Interlibrary loan is an element of extremely vital importance to the prison library. It is a lifeline to the outside world and can be utilized to obtain materials that are new or in high demand or which represent one-of-a-kind requests. By its very nature, a successful interlibrary loan program is able to save a library thousands of dollars over the course of several years. In the past many public and academic libraries were loath to send materials to prisons because of the potential for damage, loss, or theft. This prejudice has been countered and minimized, as more prisons have employed professional librarians. The librarian, however, must be exceptionally diligent in guaranteeing the care and safety of interlibrary loans, a process that can be very lime-consuming and fraught with difficulty. In addition, he or she must apply institution standards to all incoming materials, examining them for content that is contrary to "penological interest".

Building a prison library collection is a difficult task because funds are scarce. Since prison construction is proceeding so rapidly and prison populations are swelling at an unprecedented rate, funding is often diverted to construction, security equipment, and the hiring of security officers. Almost every prison has a continual budgetary shortfall. The prison library is often overlooked in these circumstances, and apportioned funds are often redeployed. The librarian is forced to battle fiercely for funding and struggle to maintain that which was allotted. Even with an aggressive stance, librarians find themselves short of purchasing power during the course of any given year-especially when faced with the escalating cost of print materials. Because of this fact, the entire process of collection development is retarded, and the librarian is forced to exercise a more judicious and careful approach to purchasing. There is little room for hit -or-miss buying or experimentation.

\section{Library Usage}

The prison library is a vital, high-usage area, but in many prisons, especially those at high levels of security, access to the library is strictly controlled by security procedures. At Columbia Correctional Institution, the library is open forty-seven hours each week, and when the librarian is not present, it is managed by a security officer, who is aided by the library clerks. Inmates are assigned library time by housing unit and forced to choose between a visit to recreation (the gym) or the library. At other 
institutions, inmates are issued movement passes and must wait their turn to use the library. At lower levels of security, inmates are often allowed relatively free access to the library.

During the 1999 calendar year, 23,840 inmates visited the library at CCI, an average of 36 visits per year by each general-population inmate (670 inmates). Inmates borrowed 28,509 items, including law materials and interlibrary loans, an average of 33 books per inmate ( 870 inmates). Of this total, 3,536 were interlibrary loan transactions, an average of five items per inmate (670 inmates). These totals, of course, do not include materials used for browsing (e.g., newspapers and periodicals), legal work, or reference. The intensity of use becomes more apparent if one considers the fact that approximately forty percent of the inmate population falls into the category of "active library user". Other inmates are disinclined to use the library because of illiteracy, because they feel themselves intellectually debilitated by all-day school programs, or because they prefer to frequent the gymnasium.

In addition to on-site users, the CCI library operates an extensive outreach program that is designed to deliver books and legal materials to approximately two hundred inmates who are confined in segregation areas or have been placed on some other type of restrictive status. In 1999, the library processed and responded to 5,045 written requests from such inmates, delivered 4,348 collection items to them and provided them with numerous responses to general and legal reference requests. The major ancillary functions of the CCI library are the production of photocopies and the provision of notary service to both staff and inmates. During the past year, 129,419 photocopies were produced, and 796notary transactions were completed. In addition to these services, the librarian and inmate clerk staff furnished inmates with product catalogs, aided them in filling purchasing orders, distributed legal forms, compiled bibliographies (upon request), handed out Internal Revenue Service forms, advised those preparing tax returns, and distributed free publications, such as team sports schedules.

In dealing with inmate library patrons, one must be constantly aware of their demand for immediacy - a demand that sometimes approachies irrational desperation. They are often unwilling to wait for the delivery of either service or materials. For this reason, the on-site collection of the library must be adequate to the felt needs of the majority so that immediate, on-hand response may be given. Such demand results in shaping the collection to reflect only inmate tastes, while sacrificing the principles of balance and comprehensive scope. This pressure for immediacy also results in uncomfortable tension between the librarian and library clerks and their patrons. Inmate clerks, in particular, feel extremely hard-pressed by their peers when they are unable to provide adequate responses to such demands, and in such situations demands tend to escalate. Thus, every day, the satisfaction of individual patrons diverts the librarian from long-term, planned activities. For example, simple library activities, such as cataloging or book purchasing, may be put off day after day, or the librarian may labor several days on a sheet of statistics which should have been completed in two or three hours.

Heavy library usage brings a host of problems with it. The library can evolve into a recreational and social area. Inmates may come to the library simply to meet and hold conversations. The noise level in the typical small, prison library tends to be magnified by the surroundings and difficult to control. In this environment, gang confabulations and the passing of contraband items flourishes. Book thefts and mutilation of materials increase. If the library does not have a security officer attached to it, the librarian is often forced into the role of security adjunct, for he or she is compelled to keep order and serve as library watchdog.

Excessive library usage of limited materials also translates into rampant collection erosion. Print materials are battered, beaten, twisted and mauled. They may be drenched with water when recalcitrant inmates plug up drains and flood their cells or damaged by fire when angry prisoners ignite their mattresses and personal papers. Cryptic messages, gang signs, or racial epithets may be scrawled on the pages of the most popular books; wouldbe artists may remove illustrations for copying or tracing; and thieves pass books from hand to hand until they disappear into a mysterious black hole - a seemingly impossible void in a tightly controlled correctional institution. Correctional librarians expend a great deal of time and energy in combating these sorts of problems (e.g., requesting searches, supervising book repair, replacing volumes, etc.), as they concentrate on resurrecting rather than building.

\section{The Future}

Prison libraries demonstrably lag behind their counterparts in academia and the public and private sectors, and institutional librarians remain librarians rather than contemporary information scientists. The future, however, is not dim, nor is the librarian's labor necessarily sisyphean. Correctional system administrators no longer conceive of libraries as only an after-thought and realize their importance to the mission of corrections. When prisons are renovated or constructed, libraries are considered to be necessary program units and provided with pre-designed locations. Library planning has become more centralized and coordinated. Long-range library plans have been developed, and there is movement toward standardization of resources and services. Automation has been introduced into the library mix. 


\section{6

The ranks of institutional librarians have become increasingly professional, as persons with library and information science training and credentials move into open positions. For professionalization to become a daily reality, however, there are a number of conditions that must be satisfied. First, the space allotted to libraries must be adequate and the physical conditions of such areas must be both livable and attractive. Second, correctional libraries should be expanded beyond the single-person paradigm. Adequate staffing is necessary to guarantee both a high level of service and to allow librarians to develop and manage their areas by goals and objectives. Third, librarians should be involved as little as possible in security initiatives. Full-time correctional officers should be assigned to each library to monitor inmate behavior, effect disciplinary actions, and maximize library accessibility. Fourth, correctional administrators should insure that prison libraries are well funded and guarantee the integrity of these funds so that library development may be well planned and progressive. Fifth, automated technology, especially on-line capability, must be more fully integrated into the library fabric because of its capability to deliver information cheaply, efficiently, and immediately. If these conditions are realized, prison libraries will only then begin to become true libraries-libraries of the New Millennium.

Glen Singer has degrees in Political Science, Classics, and Library Science. He has been employed in the correctional field for the past 21 years and is currently Librarian at Columbia Correctional Institution, 2925 Columbia Drive/P.O. Box 950, Portage, WI, USA, 53527.

Phone: (608) 742-9100 ext. 247; Fax: (608) 742-9111;

E-mail: glen.singer@doc.state.wi.us 